\title{
Multitasking and Mentalizing Machines: How the Workload Can Have Influence on the System Comprehension
}

\author{
Oronzo Parlangeli ${ }^{1}$, Maria Cristina Caratozzolo ${ }^{2}$, and Stefano Guidi ${ }^{2}$ \\ ${ }^{1}$ Department of Social, Political and Cognitive Sciences, University of Siena \\ parlangeli@unisi.it \\ ${ }^{2}$ BSD Design \\ \{cristina.caratozzolo, stefano.guidi\}@bsdesign.eu
}

\begin{abstract}
The laboratory study we are carrying out is aimed at discovering possible correlations between multitasking activity, workload and the attribution of mental states to technological systems. The scores of mental states attribution provided by subjects allotted to three different experimental conditions (one task, two concurrent tasks, three concurrent tasks) have been compared. Preliminary results show an increase in the tendency to attribute mental states as the operational workload increases.
\end{abstract}

Keywords : multitasking, attribution of mental states, workload.

\section{Introduction}

Research in cognitive ergonomics has often taken for granted that human-computer interactions are based on the elaboration of some interpretative models. That is, expectations about the way a system works come from the mental models progressively elaborated by the user through the consideration of the computer behavior. These models are traditionally considered as deterministic models of processes, sometimes they are incomplete or not coincident with the actual functioning of the system, but quite often they are sufficiently adequate to give course to a productive interaction.

More specifically, the user is believed to elaborate mental models that would be used as a means to make predictions, to produce explanations, and to provide diagnosis about the behavior of the system (Allen, 1997).

As a consequence of that, the communication between man and machine is in fact set on the basis of the understanding that the user is able to build about the system, and will therefore be much more efficient, as the latter will be more accurate.

The common experience is that human beings generally interact with inanimate systems making use of an implicit knowledge of proper physical laws. Though, in some cases that have been extensively investigated, the interaction with many mechanical systems, and particularly with information and communication technologies, seems to be based on other interpretative rules (Molina et al., 2004). It 
is well known that people tend to consider as human agents those systems that move and/or show some changes in even simple characteristics, such as shape, color, and size (Dittrich 1994, Morewedge 2007). This bias, that is the liability to consider human-made systems as if they were human beings, seems to depend on conceptualizing these systems as if they were gifted with some self-generated and self-controlled cognitive ability (Epley et al. 2007, Kelemen, Carey 2007, Terada 2007 ).

It seems quite clear that this phenomenon involves one of the human tendencies that is probably amongst the most surprising and advantageous from an evolutionary point of view, namely the bias that brings us to attribute mental states, to elaborate a theory of mind (Premack and Woodruff, 1978; Dennett, 1987), to and for nearly all the entities with which we engage in some kind of interaction.

In the last years, the human tendency to anthropomorphize - in this context it could be said "mentalize" - nearly everything, has been gaining increasing attention. For what concerns the explanation of how a theory of mind is developed by human beings since their birth, it is possible to identify two opposite hypoteses, the one seeing this tendency as innate (Baron-Cohen, 1995; Premack, 1990; Perrett and Emery, 1994) and the one framing it as a competence that is structured mainly through actual experiences (Meltzoff, 1995; Tomasello 1999).

Some recent studies (Steinbeis and Koelsch, 2009) in the field of neuropsychology have shown that when people believe that they are interacting with an artifact, that is with a human product, it is possible to record a cortical activity that is in the same cortical network (anterior medial frontal cortex - superior temporal sulcus - and temporal poles) that is usually activated during processes of mental states attribution

In the field of human-computer interaction, however, this issue has never received much attention. This in spite of the fact that understanding the way in which users elaborate a theory of mind for what concerns computer behaviors could be clearly very useful to design and implement more user-friendly technological systems.

Some studies have been conducted in order to investigate which determinants can induce the adoption of a theory of mind in relation to the behavior of some robots technological systems that often, even in their appearance, can closely resemble human beings. In these cases, the studies have generally supported the hypothesis that considers human beings more prone to the attribution of mental states if the interactive systems exhibit actions that are reactive to user behavior, and if their affordances can be more easily detected.

Overall, however, there is still a surprising lack of knowledge about the phenomenon of mental states attribution to artificial complex systems. So far, for instance, we do not know whether the attribution of mental states is an all-or-nothing process, or whether different mental states, such as intentionality and awareness, are seen linked together in the process of attribution of a mental entity. It is also actually unclear if some contextual variables, that are neither inherent to the user nor to the system, may affect the occurrence of such a phenomenon. 


\section{$2 \quad$ Multitasking}

Multitasking can be described as the behavior that allow people to cope with more than one task at a time. Research has recently provided evidence that during the last decades, likely due to the increased availability of technological systems, multitasking has become a very common behavior, and it is relatively more common among the younger generation (Roberts et al. 1999; Foehr 2006).

Reasons for engaging multitasking activities have not only been related to the growth in number of the technological systems. Other theoretical perspectives have focused on the psychological determinants for multitasking. Different authors (Albarran et al. 2006; Pornsakulvanich, et al. 2008; Zhang and Zhang, 2012) have referred to the theory of uses and gratification as an explanatory hypothesis for multitasking while interacting with ICTs. In this perspective, gratifications are considered as one of the most relevant factors in shaping human-computer interaction. More recently Sanbonmatsu et al. (2013) have suggested that those people who are more prone to engage in multitasking activities are also less able to block out distractions and to dedicate all their attentional resource to a single task.

Then, the willing of an individual to undertake multitasking activities with technological systems probably depends either on contextual factors, such as the availability of technologies, and on psychological factors, such as the control of his cognitive resources.

In a reference to the use of cognitive resources, an obvious effect - often particularly emphasized by popular science - is highlighted: multitasking activities can erode cognitive resources in a consistent manner. It follows that in multitasking activities the performance of each individual task can degrade until the occurrence of the condition in which different tasks, contending the same resources, cannot be executed properly.

Is now a widely accepted hypothesis that for the execution of various tasks the same systems and the same cognitive processes can be committed.

Just think of the enormous deal of research that, basing on the evidence of interference in the performance of dual tasks, led to the development of theories such as those concerning the existence of different subordinate systems referring to working memory (Baddeley and Hitch, 1974). Well-known findings on this field tell us that tasks that must be performed at the same time can be especially difficult if, for example, they are similar to each other (Treisman and Davies, 1973) and if the subjects are not experienced, and therefore the necessary tasks for their planning and execution have not been automated (Everett, 2011).

According to these considerations, may be therefore informative to know whether subjects that are more likely to engage in multitasking activities with technological systems are more or less inclined to attribute mental states to technologies; namely, to clarify if and how an augmentation of the workload (not only at a cognitive level) has an effect on the processes that lead to the discrimination of mental agents from those that are not. 
As a matter of fact, this could be illuminating, for example, on the role of the attentional processes in the process of anthropomorphization or in the acquisition of an intentional stance. It may also suggest some hypotheses on the development of the discerning capacity underlying the mental processes that discriminate intentional agents from those that are not.

Finally, it could provide indications that the younger generation, given the large amount of time they spend interacting simultaneously with multiple technologies, might live in a world that is populated by systems that are perceived as more or less intentional than their parents do.

Trying to answer these questions, a laboratory study is being carried out; it involved 60 subjects. In the following we will give account of this study, trying to report the most important preliminary results.

\section{The Study}

The laboratory study we are carrying out is aimed at discovering possible correlations between the accomplishment of a multitasking activity, the increase of workload and the attribution of mental states to technological systems.

In order to pursue this aim, the experimental session is structured in three different phases: an initial questionnaire, the actual task, and finally another questionnaire, for a total duration of approximately forty minutes.

To begin, the subjects are invited to provide some general socio-demographic information and some indications on their use of media tools and applications.

Then, a tool developed by Ophir et al (2009) is used to deduct if and how much the subjects use different media simultaneously. The media taken into consideration are: Social media, TV, computer videos, music, video games, telephone, instant messaging, text messaging, e-mail, web, other computer applications.

The subjects must complete a matrix in which each of the above-mentioned media is considered as the primary mean: They have to report how often they use simultaneously (as a secondary mean) each one of the other media (see Figure 1).

Thanks to the information provided in this matrix, it is possible to derive the Media Multitasking Index (MMI), which defines at what level the subject is - or is not - a multitasker.

After the pre-test questionnaire, the subjects are asked to perform the proper laboratory test; they are randomly allotted in three groups, and requested to perform tasks of increasing complexity. The first group faces a, quite simple, single task, while the second and third group have to perform a multitasking activity - two and three tasks at the same time, respectively. 


\begin{tabular}{|c|c|c|c|c|c|c|c|c|c|c|c|c|}
\hline \multicolumn{4}{|c|}{ Privi usando dei numeri per indicare le parole: } & \multicolumn{2}{|c|}{1 -mai } & \multicolumn{2}{|c|}{2 - raramente } & - a volte & \multicolumn{4}{|c|}{ 4- spesso } \\
\hline 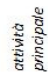 & $\begin{array}{l}\text { attività } \\
\text { secondaria }\end{array}$ & $\begin{array}{l}\text { social } \\
\text { network }\end{array}$ & $\begin{array}{l}\text { Guardila } \\
\text { TV }\end{array}$ & $\begin{array}{l}\text { Guardidei } \\
\text { video al } \\
\text { computer }\end{array}$ & $\begin{array}{l}\text { Ascolti } \\
\text { musica }\end{array}$ & videgiochi & $\begin{array}{l}\text { Parli al } \\
\text { telefono }\end{array}$ & $\begin{array}{l}\text { instant } \\
\text { messaging }\end{array}$ & sms & e-mail & web & \begin{tabular}{|l} 
Altri \\
programmi
\end{tabular} \\
\hline \multicolumn{13}{|c|}{$\begin{array}{l}\text { Interagendo sui social } \\
\text { network }\end{array}$} \\
\hline \multicolumn{13}{|c|}{ Guardando la TV } \\
\hline \multicolumn{13}{|c|}{$\begin{array}{l}\text { Guardando deivideo al } \\
\text { computer }\end{array}$} \\
\hline \multicolumn{13}{|c|}{ Ascoltando musica } \\
\hline \multicolumn{13}{|c|}{ Facendo dei videgiochi } \\
\hline \multicolumn{13}{|c|}{ Parlando al telefono } \\
\hline \multicolumn{13}{|c|}{$\begin{array}{l}\text { Usando programmi di } \\
\text { instant messaging }\end{array}$} \\
\hline \multicolumn{13}{|c|}{ Scrivendo o leggendo sms } \\
\hline \multicolumn{13}{|c|}{$\begin{array}{l}\text { Scrivendo o leggendo } \\
\text { e-mail }\end{array}$} \\
\hline \multicolumn{13}{|c|}{ Navigando sulweb } \\
\hline $\begin{array}{l}\text { Usand } \\
\text { progra }\end{array}$ & $\begin{array}{l}\text { qualsiasialtro } \\
\text { nmaal computer }\end{array}$ & & & & & & & & & & & \\
\hline
\end{tabular}

Fig. 1. The Italian version of the Ophir et al (2009) tool, used to define the MMI index

To be specific: The subjects of the first group only see the squares on the screen (refer to Figure 2), which change their colour every 2 seconds; they only have to press a key if at least 3 out of 4 of the rectangles are the same colour.

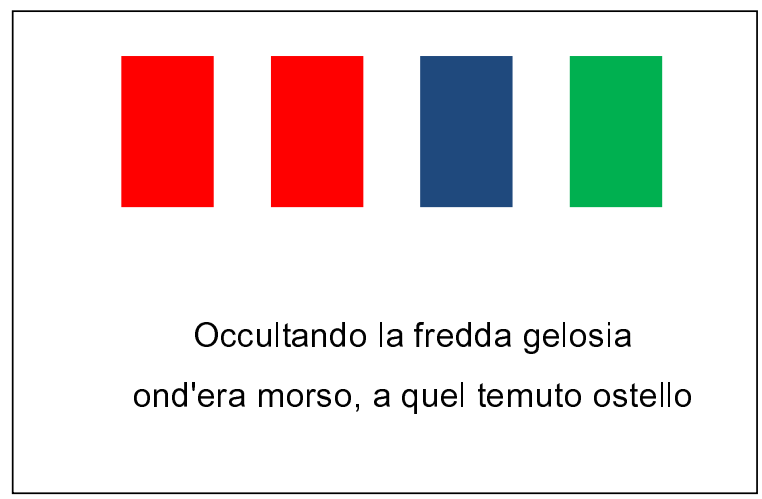

Fig. 2. The stimuli of different experimental conditions

The subjects in Condition 2 can also see the lines of a poem of the XIX century (two hendecasyllables that remain on the screen for 4 seconds) and, in addition to performing the task of Condition 1, they must also read those verses aloud. 
The subjects in Condition 3 perform the previous two tasks and, moreover, they have to click with the mouse when they read a verse with at least one comma.

In all three conditions, the duration of the whole task is about 7 minutes and 30 seconds.

The third phase of the experimental session consists of two steps. First, the subjects are required to complete a questionnaire concerning the attribution of mental states: They are asked to report if, in the course of the interaction, they happened to think that the coloured rectangles/the application had: Awareness, their own strategy, intentions, a mind, capability for attention, recollections, etc.

Finally, in order to verify that an increase of the number of simultaneous tasks also increases the workload, the subjects must also complete the NASA Task Load Index (NASA-TLX): It is a subjective workload assessment tool developed by the Human Performance Group at NASA's Ames Research Center. It allows users to perform subjective workload assessments on operators working with various human-machine systems, through a multi-dimensional rating procedure that derives an overall workload score based on a weighted average of ratings on six subscales.

These subscales include: Mental Demands, Physical Demands, Temporal Demands, Own Performance, Effort and Frustration.

\section{$4 \quad$ Results}

The preliminary results of this study are showing a clear relationship between performance of multitasking and taking an intentional stance. We compared the subjects' believes about the system having mental states across the different experimental conditions, using both MANOVA and non-parametric tests. Both kinds of tests showed significant differences between the conditions for 5 mental states attributions: Awareness $(\mathrm{p}<0.05)$, Intentions $(\mathrm{p}<0.05)$, Attention $(\mathrm{p}<0.01)$, Memories $(\mathrm{p}<0.05)$, Mind $(\mathrm{p}<0.05)$. As a matter of fact, the subjects reported that they attributed mental states to the rectangles on the screen with greater ease and frequency, as the number of tasks they had to perform increased (Figure 3). Pairwise comparisons, however, for most mental states showed significant differences only between the control condition (no multitasking) and the double multitasking condition, and no differences between the two different multitasking conditions, although this could be due to a lack of statistical power in this early stage of the study. As a matter of fact, the analysis of the mean NATA-TLX scores across the conditions, confirmed that indeed the perceived workload significantly increased with the number of tasks to be performed $(\mathrm{p}<0.0001)$, but also showed significant differences in all the pairwise comparisons. 


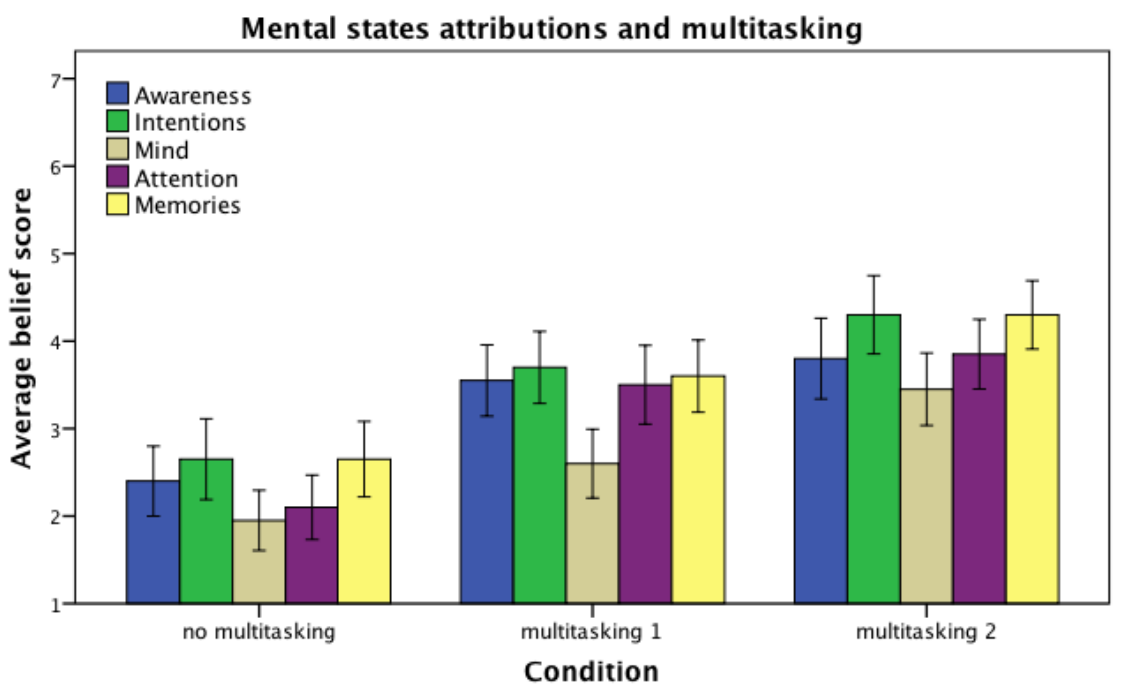

Error bars: + /- $1 \mathrm{SE}$

Fig. 3. Bar plots represents the average belief scores for five different mental states, as function of condition (i.e. presence and degree of multitasking). Error bars are standard errors.

This willingness to attribute mental states, finally, does not seem to be correlated with the MMI index, namely the individual tendency to undertake multitasking. It therefore seems possible to conclude that the more a person is induced to operate in multi-tasking activities, the more will be brought to believe that the technologies with which they are dealing with mental states.

\section{Discussion}

In his seminal work Dennett (1987) has put forward that the choice of which particular stance must be adopted depends on factors as the level of accuracy that the task at hand requires to be properly performed, and by how successful that stance has resulted in similar circumstances when formerly applied.

Several studies, however, have shown that both contextual and personal factors can affect and change the tendency to attribute mental states to the artifacts and technologies surrounding us.

In a previous study (Parlangeli et al. 2013) the authors noted a clear relationship between the multitasking and the attribution of mental states to technological systems: the more a subject declares him/herself as a multitasker, the more he/she reports of having experienced circumstances in which he/she thought that his/her computer had mental states.

An open question remained, however, about whether this is due to the fact that individuals who are more likely to undertake multitasking activities are also more willing to assume an intentional stance with regard to the technological systems, or 
that it is the multitasking activity itself, requiring a considerable commitment of the cognitive resources, brings to an easier attribution of mental states to technologies contextually.

Consequently, the present study opens new perspectives of interpretation of this phenomenon. On the one hand, it follows that the subjects that are frequently pursuing a multitasking are more inclined to attribute mental states to the technologies they use. On the other hand, this data are further defined by the reference to the mental workload required to perform these tasks, and probably to a considerable use of attentional resources: Individuals who are brought to operate in multitasking mode are more inclined to attribute mental states to technologies.

This allows us to suppose that the ability to discriminate mental from non-mental agents can be partially weaken by our attentional resources being maximally involved in the execution of multiple tasks. As if to say that, when we are particularly committed by a cognitive point of view, perhaps we fail to assume a correct, but costly, rational attitude.

It also seems possible that, in maximum operational commitment circumstances, less evolved cognitive procedural rules could emerge, rules that are not able to lead to a fine discrimination between mental and non-mental entities.

\section{References}

1. Albarran, A.B., Anderson, T., Bejar, L.G., Bussart, A.L., Dagget, E., Gibson, S., et al.: What Happened to our Audience? Radio and New Technology uses and Gratifications among Young Audult Users. Journal of Radio Studies 14(2), 2-11 (2006)

2. Allen, R.B.: Mental models and user models. In: Helander, M., Landauer, T.K., Prabhu, P. (eds.) Handbook of Human-Computer Interaction. Elsevier Science (1997)

3. Baddeley, A.D., Hitch, G.: Working Memory. In: Bower, G.A. (ed.) Recent Advances in Learning and Motivaation. Academic Press, New York (1974)

4. Baron-Cohen, S.: (1) Mindblindness: An Essay on Autism and Theory of Mind. The MIT Press, Cambridge (1995)

5. Baron-Cohen, S.: (2) The eye direction detector (edd) and the shared attention mechanism (sam): Two cases for evolutionary psychology. In: Moore, C., Dunham, P.J. (eds.) Joint Attention: Its Origins and Role in Development, vol. 3, pp. 41-59. Lawrence Erlbaum Associates (1995)

6. Dennett, D.C.: The Intentional Stance. Bradford Books/MIT Press, Cambridge, Mass. (1987)

7. Dittrich, W.H., Lea, S.E.G.: Visual perception of intentional motion. Perception 23(3), 253-268 (1994)

8. Epley, N., Waytz, A., Cacioppo, J.T.: On seeing human: A three-factor theory of anthropomorphism. Psychological Review 114(4), 864-886 (2007)

9. Everett, J.: Implications from Dual Tasking Research: can we really do two things at once? Psychtalk 70 (2011)

10. Foher, U.G.: Media Multitasking among American Youth: Prevalence, Predictors, and Pairings. Kaiser Family Foundation, Menlo Park (2006)

11. Kelemen, D., Carey, S.: The essence of artifacts: Developing the design stance. In: Lawrence, S., Margolis, E. (eds.) Creations of the Mind: Artifacts and their Representation. Oxford University Press, Oxford (2007) 
12. Meltzoff, A.N.: Understanding the intentions of others: Re-enactment of intended acts by 18-month-old children. Developmental Psychology 31(5), 838-850 (1995)

13. Molina, M., Van de Walle, G.A., Condry, K., Spelke, E.S.: The animate-inanimate distinction in infancy: Developing sensitivity to constraints on human actions. Journal of Cognition and Development 5, 399-426 (2004)

14. Morewedge, C.K., Preston, J., Wegner, D.M.: Timescale bias in the attribution of mind. Journal of Personality and Social Psychology 93(1), 1-11 (2007)

15. Ophir, E., Clifford, N., Wagner, A.D.: Cognitive control in media multitaskers. Proceedings of the National Academy of Sciences of the United States of America (September 5, 2009)

16. Parlangeli, O., Guidi, S., Caratozzolo, M.C.: The attribution of mental states to technological systems. Paper Presented at IV Joint Workshop Rutgers-Siena on Cognitive Sciences, RUCCS, Rutgers University (May 21, 2013)

17. Pornsakulvanich, V., Haridakis, P., Rubin, A.M.: The influence of dispositions and Internet motivation on online communication satisfaction and relationship closeness. Computers in Human Behavior 24(6), 2292-2310 (2008)

18. Perrett, D.I., Emery, N.J.: Understanding the intentions of others from visual signals: Neurophysiological evidence. Current Psychology of Cognition 13, 683-694 (1994)

19. Premack, D.: The infant's theory of self-propelled objects. Cognition 36(1), 1-16 (1990)

20. Premack, D., Woodruff, G.: Does the chimpanzee have a theory of mind? The Behavioral and Brain Sciences 4, 515-526 (1978)

21. Roberts, D.F., Foher, U.G., Rideout, V.J., Brodie, M.A.: Kids and Media at the New Millennium. Kaiser Family Foundation, Menlo Park (1999)

22. Terada, K., Shamoto, Y., Mei, H., Ito, A.: Reactive Movements of non-humanoid robots cause intention attribution in humans. In: Proceedings of the 2007 IEEE/RSJ International Conference on Intelligent Robots and Systems, San Diego, CA, USA (2007)

23. Sanbonmatsu, D.M., Strayer, D.L., Medeiros-Ward, N., Watson, J.M.: Who Multi-Tasks and Why? Multi-Tasking Ability, Perceived Multi-Tasking Ability, Impulsivity and Sensation Seeking. PLoS ONE 8(1), e54402 (2013), doi:10.1371/journal.pone.0054402

24. Steinbeis, N., Koelsch, S.: Understanding the Intentions behind man-made products elicits Neural Activity in area dedicated to mental state Attribution. Cerebral Cortex 19(3), 619-623 (2009)

25. Tomasello, M.: The cultural origins of human cognition. Harvard University Press (1999)

26. Treisman, A., Davies, A.: Dividing attention to ear and eye. In: Kornblulm, S. (ed.) Attention and Performance IV, pp. 101-117. Academic Press, New York (1973)

27. Zhang, W., Zhang, L.: Explicating Multitasking with Computers: Gratifications and Situations. Computers in Human Behavior 28, 1883-1891 (2012) 